Practices of other-initiated repair in the classrooms of children with specific speech and language difficulties

\author{
Julie Radford \\ Institute of Education, University of London, Psychology and Human \\ Development, 25 Woburn Square, London WC1H 0AA
}

August 2008

All correspondence with respect to this article should be addressed to:

Dr Julie Radford, Psychology and Human Development, Institute of

Education, 25 Woburn Square, London, WC1H 0AA., UK

Email: j.radford@,ioe.ac.uk Tel: 02076126295 


\title{
Practices of other-initiated repair in the classrooms of children with specific speech and language difficulties
}

\begin{abstract}
This paper uses conversation analysis to document four types of repair practices used by specialist teachers who work with children with specific speech and language difficulties (SSLD). Repair practices with SSLD children have hitherto been largely unexplored and therefore the classroom offers a new context for researching their design and considering how they compare with non SSLD interactions. Repair trajectories are of interest because they are dialogic sites where the child's meaning is being negotiated and, therefore, where adults might create opportunities for language learning. The interactions take place during classroom activities, such as story writing, where teachers elicit children's ideas and orient, in various ways, to their lack of clarity. From a large dataset of 78 cases, significant patterns of teacher repair initiation emerged. Non-specific repair initiators (RIs), including open class RIs, are distinguished from specific RIs on the grounds that the former target the trouble source in a general way. In contrast, specific RIs, such as designedly incomplete utterances, pinpoint the location of the trouble whilst 'wh' questions target the nature of the trouble and are used to elicit further information. Offers of candidates, as a form of correction, provide new models of lexical or grammatical information but do not elicit repetition from the child. The study provides a clearer account of the work done by teacher feedback moves that initiate repair.
\end{abstract}




\section{Practices of other-initiated repair in the classrooms of children with specific speech and language difficulties}

\section{INTRODUCTION}

Many children in schools experience specific speech and language difficulties (Dockrell et al. 2006), also widely referred to as children with specific language impairment. These children are characterised, in particular, by lexical and grammatical language difficulties (Leonard 2000) that may impact on interpersonal communication. Education is typically delivered in schools where they receive additional resources from trained language teachers and speech and language therapists/pathologists (Law et al. 2000). The priority of specialised professionals is to develop the children's understanding and use of grammar and vocabulary, to develop interpersonal communication skills and to facilitate access to the curriculum (Dockrell and Messer 1999).

The fact that children with specific speech and language difficulties spend a large proportion of their time in regular classrooms, where the vehicle of instruction is primarily oral (Cazden 2001; Edwards and Westgate 1994), places them at a significant disadvantage. Their dilemma for accessing the curriculum is exacerbated when teacher-pupil discourse is primarily targeted at whole class groups, such as during mathematics and literacy lessons (Mroz et al. 2000; Smith et al. 2004). Arguably the most important factor concerns the quality of the interaction itself. International research continues to report the prevalence of interrogative and evaluative styles of talk in primary-aged classrooms (Alexander 2001), despite many efforts to foster the increased participation of children during interactions. A well documented system, called the 'IRE/F', constrains the participation of teachers and 
students (Mehan 1979; Sinclair and Coulthard 1975). It is characterised by the teacher initiating a 'test' question (I) that is followed by a known answer/response (R) (Macbeth 2004). The third turn position, following the child's response, is where evaluation (E) typically occurs, although there is potential for other devices that build upon the child's turn, such as follow-up (F) or extension moves (Wells 1993) and uptake questions (Nystrand 1997). In IRE/F discourse contexts, however, children with specific speech and language difficulties run the risk of becoming passive and lacking engagement in their learning (Radford and Ireson 2006). Minimal participation may lead to reduced opportunities for language learning because topicrelated exchanges are shortened and trouble sources may remain unresolved (Sadler and Mogford-Bevan 1997).

An alternative to interrogative and evaluative talk is dialogic discourse which is evident during some types of classroom activities, for example in France, England and India (Alexander 2001; Skidmore 2000). Dialogic interactions provide higher quality learning experiences for children than talk that is teacher-led (Mercer 1995; 2000; 2007). Dialogic talk is characterised by (at least some) questions that provoke thoughtful answers, the sharing of ideas between teachers and students, children's free articulation of ideas and the chaining of ideas for a common purpose (Alexander 2006). Children with specific speech and language difficulties could benefit from dialogic discourse provided that the language is accessible and allowance is made for their expressive difficulties. There is preliminary evidence that specialist language teachers engage in dialogic teaching with children with specific language difficulties during small group activities such as story writing and news telling (Radford et al. 2006). Drawing on studies into the co-construction of topic using conversation analysis (CA) (Button and Casey 1984; 1985; Radford and Tarplee 2000; Ridley, 
Radford and Mahon 2002), the authors demonstrate how the children and their teachers co-construct topic on a turn-by-turn basis.

Two examples are now provided that are relevant to the data analysed in the current study because children's own ideas are generated in these contexts. Owing to the children's language difficulties novel ideas, as we shall see in the later analyses, frequently necessitate the initiation of repair. The resulting trajectory of talk that deals with the repair is, arguably, an example of dialogic discourse. The first example, an 'invitation' sequence, has been found when teachers construct a story with a group of children (Extract A, taken from Radford et al. 2006). Invitation sequences differ from question-with-known-answer sequences because, although they are suited to constraining the child's response in terms of adherence to a story-line, they accomplish the generation of the child's novel story ideas. As such, the teacher is not predicting precisely what ideas the child will offer, and therefore what $\mathrm{s} / \mathrm{he}$ will subsequently receipt as a relevant contribution.

\section{Extract A (Note 1) Story invitation sequence}

$\rightarrow 1 . \mathrm{T}:$ [right Eddie are you ready? (1.2) one day there was a [((T looks at Eddie-
$\rightarrow$ 2. Ch: (1.2)
a little boy

\section{T looks at E \& holds out hands))}

$\rightarrow 3 . \mathrm{T}:$ a little $\uparrow$ boy one day. there was a [little boy

4. Ch: [playing at the seaside

5. $\mathrm{T}$ : he was play a little boy at the seaside whho:: $\mathrm{s}$ [so we've got a person [((draws little boy----.

6. $\quad$ and a $\uparrow$ place right there’s a little boy? (3.2) happy boy? 
--------draws eyes, nose------------------------lowers hand

(Radford et al.

2006)

Extract A begins with the teacher's (T) story starter line ('there was a'), that is designed to be incomplete and, therefore, completed by a nominated child. The child (line 2) treats T's turn as a request to contribute an idea concerning the story's character. Other examples of next turns include children's ideas relevant to the story's title, the setting or the plot. The teacher's response to the child's ideas is not an evaluation, but an 'acceptance' which can take a variety of forms. In line 3 it is a repeat of the child's idea and, in some cases, the verbal idea is drawn onto a flipchart to make a visual representation of the story constructed so far (lines 5-6).

The second example is found during a one-to-one speaking-book activity where the teacher and child are discussing pictures and photographs that the child has chosen. These pictures have been brought from the child's home and the teacher has not seen them before. Extract B shows the teacher using a topic initial elicitor (TIE) (Button and Casey 1984) which is heard by the child as a request to offer ideas. The TIE sequence differs from a question-with-known-answer sequence because the child treats it as an opportunity to choose his/her own topical material, albeit within the constraints of relevancy to the picture. In the case of photographs, the child may offer personal news ideas whereas, in the case of pictures, the ideas may concern a description of any detail of the picture (Radford et al. 2006).

\section{Extract B Topic initial elicitor sequence}

1. T : right. what other pictures I haven't seen the:se pictures either. (.) 
$\rightarrow 2$. tell me about those.

$\rightarrow$ 3. Ch: uhh there's a kitten and she's looking for mice.

$\rightarrow 4 . \mathrm{T}: \mathrm{mhm}$

5. (0.5)

6. Ch: and when he eat the mice he gonna die.

(Radford et al. 2006)

In line 2, the teacher's TIE at first appears to resemble an instruction, although it could take the form of a request for a telling 'can you tell me..'. However, the child treats it as an open inquiry and offers her own ideas to describe the picture (line 2). The teacher responds to the ideas with topicalisation of the material generated so far (Button and Casey 1984; Radford and Tarplee 2000). Here we find 'mhm', a continuer that does the job of topicalising in this context. The child orients to the topicaliser and the silence with continuation of her description (line 6). If, instead of topicalisation, the teacher had elected to evaluate the child's response and asked a test-like question, the child would have been denied the opportunity to pursue the topic that she had nominated herself.

As invitation and TIE sequences are suited to the generation of ideas by the children, they provide potentially richer resources for language learning than knownanswer questions that generate short, unexpanded responses. Sequences that have further potential, but have not yet been investigated, are where acceptance or topicalisation of the children's ideas is withheld. Instead, the participants suspend the usual sequence in order to deal with a trouble (see Schegloff, 1972, on insertion sequences). Children with specific speech and language difficulties, owing to the very nature of their linguistic problems, produce turns that contain grammatical or lexical 
errors or risk being unclear to the listener. When teachers initiate repair (usually) in the next turn, the insertion sequence deals contingently with the child's trouble. During the insertion, the teacher might provide correction (Jefferson 1987), which in language teaching would take the form of a more competent model of grammar or lexis, as compared with the child's version. Another possibility is that the teacher might initiate repair such that the child is placed to revise her/his original move.

This paper aims to explicate, in detail, a series of practices where teachers and children are dealing with repair, when acceptance or topicalisation of the child's idea is withheld. More specifically, the paper will pay particular attention to the design of the teachers' initiator techniques and the actions accomplished by them. Owing to the pedagogical interests of the researcher, the analysis will highlight the relative strength of the repair initiator (RI) to locate the problem with speaking/hearing/understanding (Schegloff et al. 1977; Schegloff 1997). Techniques that provide the least help in locating the trouble, such as open class RIs (e.g. 'pardon') (Drew 1997) will be compared with those that locate the repairable more specifically and/or supply a candidate offer to the child. Some tentative suggestions will be made concerning the ordering of these devices in oral language lessons. As there is no parallel work in the classrooms of children with specific speech and language difficulties, the findings will be compared to those of studies conducted by conversation analysts in first and second language discourse contexts.

\section{PARTICIPANTS, DATASET AND METHOD}

The adult participants were three specialised teachers who had all worked in Language Units for at least 10 years. Whilst they were not qualified as speech and language therapists/pathologists, they did have post-training qualifications in the area 
of language development and specific language difficulties. There were six children, aged $4 \mathrm{y} 4 \mathrm{~m}$ to $8 \mathrm{y} 7 \mathrm{~m}$ at the time of the first visit, who all had 'statements' of special educational need that indicated the need for Language Unit provision. Information about the nature of their language difficulties was collected by questionnaire that was completed by the teacher and speech and language therapist together. Table 1 shows that the children had mainly receptive and expressive language difficulties (Note 2), characterised also by semantic problems. Children with significant speech difficulties such as verbal dyspraxia, phonological difficulties and pragmatic difficulties (Note 3) were excluded.

\section{[TABLE 1 NEAR HERE]}

Story writing, book-sharing and circle-time activities were selected by the teachers as best examples of oral language teaching. Story writing and circle-time activities were conducted in small groups of 5-6 children, although two target children in each activity were the focus for the analysis. Book-sharing was conducted on a one-to-one basis with the teacher. Video-recordings were made with a digital camera on four separate occasions, yielding a dataset of twenty-four lessons (8-45 minutes long). Radio-microphones were positioned on the teacher and quietest of the two target children in the group activities to help to increase the accuracy of the recordings. Repeated viewings were made followed by detailed transcriptions of selected segments.

Given that, apart from aforementioned work, there are no detailed studies of interaction in the classrooms of children with specific language difficulties, one possible analytical approach would be to borrow or adapt a coding scheme used in 
second language classroom research. This was rejected for several reasons. In terms of children's moves, coding single turns, for instance as phonological, lexical or grammatical 'errors' (Lyster 1998), would be inappropriate because a) many of the turns contain multiple sources of trouble and b) unclear content is a common source of trouble in specific language difficulties data but it only becomes apparent from the teacher's display of difficulty in the subsequent turn or turns. Similarly, coding single teacher moves as, for example, repetitions, recasts or requests for clarification (Loewen 2004) would be problematic as shown in the analysis. This study thus adopts conversation analysis (CA) perspective in order to represent 'how participants themselves produce and interpret each other's actions' (Pomerantz, 1988; 361). First, the author made a collection of 245 instances of repair of which 78 cases appeared, superficially at least, to be dealing with repair initiated in response to the child's idea. The analysis next proceeded by repeated viewings of the video sequences which uncovered how apparently similar practices, such as repetitions, accomplish completely different actions (Schegloff 1997). It also showed how actions can cooccur, notably checking / correction / clarification. Furthermore, a rich and detailed analysis of participants' moves was made, including linguistic detail, non-verbal action and prosody, which is essential to fully document the competences of children with language difficulties and their teachers.

\section{FINDINGS (Note 4)}

A series of other-initiated repair (OIR) practices are described, of interest for language learning because they are dialogic sites where the child's meaning is potentially being negotiated. First, there is an account of OIRs that are 'non-specific' in the sense that each repair initiator has an open design that orients to the teacher's problems 
hearing/understanding the child's turn(s). Non-specific OIRs are, for the most part, treated as prompts to repeat. In contrast, the next examples are classed as 'specific' OIRs since the teacher pinpoints, in various ways, the location of the trouble, either because she leads the child into its location with a non-completed utterance, or because she uses a 'wh' question to specify its nature. Finally, examples where candidate offers are made will be explored, including requests for definition.

\section{Non-specific ('general') RIs}

What is distinctive about non-specific RIs is that when teachers signal trouble with the child's response turn, they do not, by any specific design indicator, locate the item to be repaired. As such they target potentially any aspect of the child's prior utterance. Children have different options in response: they can either repeat or reformulate their own previous material in the following turn or turns. Segment $\mathrm{C}$ illustrates three examples of 'general' RIs: a repetition request at line 3 and two statements of uncertainty (lines 5 and 7). The context of the extract is story writing with a small group of six children. The teacher $(\mathrm{T})$ has already written and drawn several of the children's ideas onto a flipchart regarding the characters and story-line and now asks the children a question.

(C) Repeat requests and uncertainty markers (Story writing: child 5; 5y)

1. $\mathrm{T}:>$ can you think of $\mathrm{a}<$ name for the story

2. $\mathrm{Ch}:(\quad)$

$\rightarrow 3$. T : say that again.

4. Ch: $(\quad)$

$\rightarrow 5$. T : ooh I'm not sure what you're saying 
6. Ch: ee:::

$\rightarrow 7$. T : ee: I don't know what that means

8. (0.2)

9. $\mathrm{T}$ : so I think something about chee:tahs

10. (0.2)

11.T : Dina and the two cheetahs?

10.Ch: yeah.

T's question (line 1) would typically be heard by the child as a request for an idea concerning the story's title. As the child $(\mathrm{Ch})$ offers a verbal contribution at line 2, T's relevant next would be to accept the idea, (often in the form of a repeat). Instead, an insertion sequence suspends production of T's acceptance to deal with a trouble. T's use of 'say that again' gives the child an unambiguous message that a repeat is needed. In fact line 3 has the appearance of an instruction, given the absence of lexical or syntactic markers of politeness. Although the child offers a response in line 4, $\mathrm{T}$ indicates continued trouble with a further non-specific marker of uncertainty (line 5). Ch next produces a non lexical item ('ee::'), so T responds with a third repair initiator, this time clearly displaying her difficulty with understanding. This also fails to solve the trouble so it is left to $\mathrm{T}$ to suggest a story name idea. A notable feature is that each of T's repair initiators target the whole of Ch's prior as opposed to marking out specific elements for Ch's attention.

Extract $\mathrm{C}$ showed three examples of non-specific RIs: a statement that a repeat is needed, and two statements that display general trouble with hearing or understanding. As the child's responses were unintelligible, further data is needed to clarify the sequential consequences of such actions. Segment D has a clearer outcome 
because the teacher indicates trouble with an open class repair initiator ('pardon', line 3) and this is taken up by the child as an opportunity to reformulate her grammar. The sequence takes place where the children are invited to suggest a plot line for the group's story. The child's subsequent ideas include both a novel character and an event. That the name 'Dina' that she supplies is searched-for is indicated by the stretched sound at the end of 'com:::' and the brief silence. The relevant next, a teacher acceptance, is once again withheld and an insertion sequence begins.

(D) Open class repair initiation (Story writing: child 5;10y)

1. $\mathrm{T}:$...what happened ne:xt.

2. Ch: the girl com::.. (.) Dina

$\rightarrow 3$. T: pardon?

4. Ch: uh Dina did come.

5. T : [个Dina came.

[((leans forward, puzzled expression) $)$

6. Ch: yeah

'Pardon' could indicate that the trouble-source entails an issue related to T's hearing and thus be heard as a request for a repeat. Yet the child's subsequent move is designed differently: while she does repeat some lexical components of her idea, she also reformulates her original word order and verb form. An explanation for the reformulation might be that open class repair initiators are claimed to treat "the whole of the prior turn as in some way problematic" (Drew 1997). The child thus orients to T's signalling of trouble with potentially any element of her turn at line 2 . As in extract $\mathrm{C}$, the open class RI is not targeting a specific component of the child's 
message for repair. Features of all non-specific designs are that T's options for repair initiation are constrained: if the child's turn is not heard or understood clearly, $\mathrm{T}$ is unable to incorporate elements of the turn in a subsequent move. In this sense, T's response is a 'general' repair initiation, as opposed to the more specific formats that will be presented next.

\section{Specific RIs (DIUs) that pinpoint the location of the trouble source}

When teacher acceptance of a child's idea is withheld, a common design for initiation of an insertion sequence, is a designedly incomplete utterance (DIU). Whilst acknowledging that there is a small dataset and more research is needed, the DIUs found in the classrooms of children with specific speech and language difficulties share the following characteristics to those reported in second language writing conferences (Koshik 2002). First, they are constructed with minimal components, either a phrase or an individual word, that borrow fragments of the child's prior turn. Next, they are used to perform different actions: on the one hand, through partial repeat of the child's turn, a DIU may elicit repetition of prior talk (Fragment E); on the other hand, it may be used to target an error and prompt the child to self-correct (Fragment F).

Extract E takes place during the early phase of the group story writing session where characters are being decided. The teacher targets Tom, using an oral cloze technique (incomplete utterance and vowel stretch), to select a character. In his turn, Tom begins with a repeat of T's modelled story starter 'there was a:::'. Prolongation of the vowel sound, constructed with continuing intonation, and the brief silence indicate that he is searching for a novel idea to offer the teacher. 
(E) DIU (Story writing: child 5; 5y)

1. T : Tom you ready? one day there was a:::,

2. Ch: there was a:::, (0.2) cheetah.

$\rightarrow 3$. T : a::, ((shakes head, leans forward))

4. Ch: a cheetah.

5. T : a chEEtah?

6. Ch: yeah

7. T: what's a cheetah?

8. Ch: it's (.) it's a (0.8) bit like a tiger.

9. T : it's like a ti:ger (.) mhm. (.) that's helpful. (.) mhm like a tiger (.)

10. do [you know what a cheetah is.

[((points at another child $))$

Although Tom offers the name of an animal, $\mathrm{T}$ withholds acceptance of this idea. Instead, she initiates an insertion sequence in line 3 with a DIU. It is a single word that is formed in a similar fashion to T's original version and the child's production: it repeats the element that preceded the lexical item, preserving the lengthening of the vowel and continuing intonation. Her trouble could have entailed hearing and is confirmed by her body language: a shake of the head and leaning posture. The child's response shows her interpretation of the DIU, thus she supplies a repeat of the noun phrase (line 4), rather than a reformulation. The repeat supplies $\mathrm{T}$ with information and she offers her candidate hearing, proffered for confirmation. Although the hearing is confirmed by the child, T pursues a definition, as if to find out 
if the child knows what a cheetah is. One notable feature of the DIU is that it targets the trouble source very precisely by leading the child, at least syntactically, up to the location of the trouble. Furthermore, the DIU has pedagogical value in so far as it generates both confirmation and definition sequences that afford further opportunities for language learning.

A similar design of DIU is found in (F) but the work that it does is different from (E) because the child hears it as a request for revision rather than for repetition. The teacher and child have just embarked on the speaking-book activity so, as they turn the page to reveal a new picture to talk about, they embark on a TIE sequence.

(F) DIU (Speaking-book: child 8; 3m)

1. T: what can you tell me about this one

2. Ch: [uh: she has (hair) ( ) (0.2)

[((T and Ch: eyegaze on picture $))$

$\rightarrow 3$. T : $[$ she has,

$[(($ T eyegaze to $C h))$

4. Ch: long

5. T : long hair. yes.

6. Ch: and she has a (.) (large) dress

The child responds to T's topic elicitor with a description of a girl (line 2), although the turn is partially unclear to both $\mathrm{T}$ and the researcher. That Ch's gaze remains on the picture suggests that she is engaged in solitary searching during the silence. At line $3 \mathrm{~T}$ withholds topicalisation and, instead, produces a DIU. It is formed by using two words of Ch's turn up to the point at which there was potentially a 
missing adjective, as seen in Ch's subsequent turn (line 4). Continuing intonation and gaze directed at the child, rather than the picture, suggests that the turn may be actioning a prompt. Ch hears it as a prompt, perhaps owing to the syntactic incompleteness of 'she has', not to produce the noun but a relevant next adjective 'long'. T hears Ch's turn and displays acceptance of the child's idea with a repeat of both the child's adjective and noun from line 2. In terms of pedagogical value, by generating further information from the child, the DIU sets up an opportunity for $\mathrm{T}$ to expand the material and supply further contingent models of language.

Like Koshik's (2002) DIUs, these two examples are not complete turn constructional units, but are recognisably complete actions that are designed, with the child's own words, to be incomplete and thus completed by the child. In response, the child is not 'interrupting', even though T's turn construction unit is not completed. The child orients to T's design (where it stops) and continues with a syntactically fitted contribution. The first example ('a::') led the child to re-produce her noun and therefore complete the noun phrase. The second, a phrase, was not only an oral invitation to complete the sentence, but also taken as an opportunity by the child to revise the next item of her original phrase. DIUs are prosodically marked here, by sound stretches and by continuing intonation which position the child to continue the phrase or sentence. DIUs, thus, target very specifically the location of a trouble. Yet, even when they are heard as invitations to self-correct, they do not give the child semantic information that could be useable in the subsequent correction. Both examples have pedagogical value in so far as $\mathrm{T}$ indicates the trouble source very specifically and generate further opportunities for targeted language practice. Finally, it is worth mentioning how the current examples are different from the writing conference examples reported by Koshik (2002). In most of the writing conference 
data, a written text was an additional available resource that was visible (at least on occasion) to the participants. In contrast, the language difficulty data are taken from oral language lessons, so the teachers are dealing with on-line discourse problems. That the children have language difficulties places an additional burden on the listener to process the children's turns accurately, especially when novel ideas are being generated in an activity like story- writing.

\section{Specific RIs ('wh questions) that pinpoint the nature of the trouble source}

The next sequences show three types of RIs that are formatted as 'wh' questions: a request to provide specific information and two requests for definition. Instead of being heard as requests for repetition, the 'wh' questions are treated as requests to supply further information. The analysis will reveal how their designs serve to pinpoint precisely, not so much the location of the trouble source, as in DIUs, but the nature of the repairable. The analysis will also show how the child orients to the RI by making a revision that provides additional information in terms of novel aspects to the story-line. Extract $\mathrm{G}$ takes place in the context of genuine news enquiry and reporting. As the child's reports are potentially 'news' to the teacher, any new ideas are susceptible to lack of clarity. The turn of interest is at line 6 , and is part of the emerging news telling sequence. The child and teacher are looking at a photograph in the 'speaking-book' and $\mathrm{Ch}$ is reporting a personal news account about taking her dog, Penny, for a walk.

(G) (Speaking-book: child 8; 7y)

1. Ch: ..and we took Penny for a walk.

2. $\mathrm{T}$ : where did you ta:ke her 
3. Ch: (1.0) uh::m

4. $\mathrm{T}$ : outside the house you mean

5. Ch: no we went a:1l the way down (.) we did.

$\rightarrow 6 . \mathrm{T}:$ [down whe:re. ]

$[(($ puzzled look $))]$

7. Ch: uh:m (.) to (see/sea) the sea

8. T : oh ri:ght? it's near the sea is it.

9. Ch: yeah

The teacher responds to Ch by asking a genuine question since she has not experienced the walk-with-the-dog. The enquiry is itemised in so far as she targets the location of the walk as a topic for further talk. The child's pause and searching behaviour ('uh::m') show that a response is being searched-for. To assist the child's search $\mathrm{T}$ offers a candidate answer of a potential location in line 4 . However, as the reported event is the child's experience, Ch holds the expert knowledge about what happened and rejects T's version ('no'). Following the rejection, Ch does supply some information that answers the itemised enquiry. At line 6, given T's puzzled look, she seems to treat this turn as providing partial information regarding the location of the walk. She thus appears to be making an itemised enquiry to elicit specific information relevant to the news report. Although the request has a minimal format, recycling just one lexical item of the child's turn ('down'), it is informative to the child. There are two important dimensions: lexically, 'whe:re' indicates that a location is the source of trouble; prosodically, loudness on 'whe:re' marks out the item that lacks clarity. In response, (line 7) Ch answers the question by supplying potentially clarifying information. Even though the analyst found it impossible to tell, because the 
ambiguity of the homophone 'see/sea' in English, whether or not the child was using a verb (see) or was self-repairing use of the determiner 'the' before the noun 'sea', $\mathrm{T}$ displays an understanding which is confirmed by the child. T's repair initiation at line 6 , then, is heard by the child as an invitation to offer further information which has the additional effect of clarifying her news report. Furthermore, at line 8, when T pursues the information generated by the RI, the child is afforded another language model that is contingent.

Extracts $\mathrm{H}$ and $\mathrm{J}$ illustrate typical definition-type requests that were widely used by the specialist teachers. Whilst the author acknowledges that more examples are needed to be confident about claims regarding their systematicity, both examples adopt a similar grammatical format ('what's X') and initiate repair on a lexical item just used by the child which displays the T's lack of understanding of Ch's usage in that context. In the first example Ch supplies different information that revises the earlier version of her lexical item. In the second example there is no revision but, instead, it is heard as a request to provide additional information concerning the trouble source. In $\mathrm{H}$ the exchange takes place in the context of picture description where, earlier in the sequence, the child had contributed a range of ideas.

At line $20, \mathrm{Ch}$ is continuing her description and is currently talking about the activities of a frog.

(H) (Speaking-book: child 8; 7y)

1. T : I haven't seen the:se pictures either have I. (.) tell me about those.

2. Ch: uh:: there's a kitten an he's looking for mice.

- (17 lines of picture talk about cats, mice and frogs) 
20. Ch: then he's gonna (.) swim over to his neighbourhood.

21. T : his neighbourhood.

22. Ch: yeah

$\rightarrow 23$. T : what's his neighbourhood

24. Ch: I mean next door neighbour

25. T : he's got a neighbour has he?

26. Ch: yeah

In UK English 'neighbourhood' (line 20) is a rare item of vocabulary and its use with respect to frogs is particularly unusual. The teacher in line 21, drawing presumably on this world knowledge, offers a candidate hearing by repeating the final two words of Ch's turn. The candidate hearing is confirmed by Ch in line 22 ('yeah'). Despite Ch's confirmation, T continues to remain confused. She displays this confusion with a specific request in line 23 to define the problematic phrase ('his neighbourhood'). The grammatical format 'what's X?' supplies Ch with information that a word definition is needed. In line 24 the child does not, however, supply a definition but responds by reformulating the trouble source. The child's self-repair in is prefaced by 'I mean' that appears to indicate a degree of metalinguistic awareness on her part about self-correction. That Ch produces the lexical item ('neighbour') at line 24 gives T opportunity for a repeat and, therefore, a further module of the correct lexis.

Extract $\mathrm{J}$ illustrates an apparently comparable request at line 5. It also emerges from prior talk that is dealing with checking mutual understanding and has the same grammatical form ('what's X'). What is different here is that, instead of being heard as a request for revision, the child is able to provide a partial definition of item ' $\mathrm{X}$ '. At 
the beginning of $\mathrm{J}$ we find a TIE sequence that generates a plot idea from the child. Although Ch offers a novel idea (given that 'sheds' have not been talked about so far), $\mathrm{T}$ withholds acceptance to initiate an insertion sequence. She repeats the last two words that the child said with additional loudness on 'SHED' and final rising intonation, as if to check for confirmation. The child offers non-verbal confirmation rather than a revision of her turn (line 4).

(J) (Story writing: child 5; 5y)

1. T : what did [they do:

2. Ch: $\quad$ ge (0.2) get a shed

3. $\mathrm{T}:$ a SHED?

4. Ch: ((nods))

$\rightarrow 5$. T : [what's a shed. $[(($ shakes head $))$

6. Ch: when it's raining[when it's raining

\begin{tabular}{l} 
7. T: $\quad$ [you've got an idea that a shed is for when it's raining? \\
\hline
\end{tabular}

8. (0.3)

9. $\mathrm{T}:$ is that right?

10.Ch: yeah

The teacher's question at line 5 signals her on-going trouble with Ch's idea, also confirmed by T's simultaneous non-verbal behaviour (shaking her head). The question has the appearance of a request for definition. How Ch heard T's request is unclear. Perhaps, owing to her language difficulty, she was unable to supply a standard definition (e.g. a small wooden building). The action accomplished here, 
interestingly, is that she supplies a novel idea that is relevant to the story-line. T's subsequent reformulation (line 7) incorporates the ideas from both line 2 as well as the new material produced in 6 . The work done by the repair initiation is therefore to achieve a definition which has the additional effect of contributing to the on-going story-line ( $\mathrm{T}$ later displays acceptance by drawing both ideas onto the flipchart). The RI also creates a sequential opportunity for the teacher (line 7) to supply an expanded model of the child's ideas, which has value in terms of language learning.

A further observation is that a candidate hearing/understanding (proffered for confirmation) precedes clarification in each of these sequences and appeared with some regularity elsewhere in the dataset. As an illustration, extracts $\mathrm{H}$ and $\mathrm{J}$ involve two teachers working with very different children of different ages and yet the pattern is similar. First of all, there is the first part of an adjacency pair, formed with a repeat of the child's noun phrase (H line 21, 'his neighbourhood'; J line 3, 'a SHED?'). This provides a candidate hearing or understanding which makes relevant the child's confirmation or correction. What appears to be happening is that, in the context of content troubles, a first move is to check that the trouble does not reside with the teacher herself: could it have entailed her own problem with hearing or understanding? In both cases confirmation is given, so a hearing/understanding problem is ruled out. Yet T's pursuit of elaboration of the item persists, which has the effect of initiating a pedagogical side sequence that targets the child's current understanding of the lexical item. A design like 'what's X' does two jobs. First, it invites the child to provide further information and, as we see here, the information is forthcoming, either as a revision or as material relevant to the topic. Next, since $\mathrm{X}$ is a component of the child's prior turn, it marks out very specifically the item to be talked about, which renders it pedagogically useful for displaying the child's understanding. 
This distinguishes the practice from the single item 'what?' technique that targets the whole of the prior (Schegloff 1997). A final, somewhat tentative observation, is that there appears to a 'natural ordering' at work, based on the relative strength or power of the teachers' techniques to locate the repairable (Schegloff et al. 1977). The teachers are employing their moves in order of increasing strength.

\section{Offers of candidates that supply a linguistic model}

The examples shown in Extract $\mathrm{K}$ are distinctive because there is material in the teacher's turns that has not been mutually shared in prior talk, according to the available data. There are two teacher moves of particular interest: at line 5 there is a candidate understanding and, at line 10 , an offer of a candidate that does the job of correction. Offers of candidates can be useful when a speaker anticipates that a hearer will experience difficulty supplying the relevant information and the speaker wants to offer help (Pomerantz 1988). The example at line 10 is formed as a modulated othercorrection 'Do you mean X?' (Schegloff et al. 1977), although at line 5 there is a variation of form. $\mathrm{T}$ and $\mathrm{Ch}$ are talking about a picture of the seaside that $\mathrm{Ch}$ has drawn to represent her story setting. At the start of the sequence the setting is being described and an additional character suggestion is made at line 3.

(K) Story writing: child 8; 3y

1. Ch: ..and seaweed under water.

2. $\mathrm{T}: \mathrm{mm}$ seaweed [under water

3. Ch: [and a nice snake.

4. $\mathrm{T}: \uparrow \underline{\text { snake }}($.$) wha d'y'mea:n in the water.=$

$\rightarrow 5 . \quad=$ in the sea? 
6. Ch: a nice snake.

7. $\mathrm{T}: \mathrm{mm}$

8. Ch: in the picture

9. T : I've never see:n a snake in the sea.

$\rightarrow 10$. d'y'mean an eel.

11. Ch: ((nods))

12. T : you get eels in the sea don't you.

13. Ch: ((nods))

Ch's idea, 'a nice snake' is treated as problematic by $\mathrm{T}$ who withholds acceptance. An insertion sequence is initiated in line 4 with a repeat of the lexical item which is formed with high pitch rise, as if to signal surprise. T makes two specific queries concerning the snake's whereabouts in lines 4-5. The first, beginning with 'wha d'y'mea:n', at first appears as a challenge to the credibility of Ch's account (Schegloff 1997). A more likely interpretation is that $\mathrm{T}$ is targeting 'in the water' for clarification of the child's meaning. Instead of waiting for a response, $\mathrm{T}$ directly offers a candidate understanding 'in the sea?' (line 5) of the Ch's turn at line 3. Ch does not respond pragmatically to T's queries or take up the offer of the candidate. Instead, she treats the turn as a hearing or understanding check, with a repeat of her phrase (line 6). No new topical material is produced by $\mathrm{Ch}$, so mutual understanding has yet to be reached which is indicated by T re-visiting the problem at line 9. This turn signals T's confusion ('I've never see:n a snake in the sea.') now making it explicit that her own world experience does not fit Ch's claim. In line 10, T offers a further candidate with the modulated other correction format 'do you mean X.' In contrast with line 5, it has falling intonation which confirms its status as a correction. Use of the verb 'mean' 
indicates clearly to Ch that the issue concerns T's understanding rather than hearing. In order to correct 'snake' to 'eel' T needed to guess by drawing on a range of contextual information.

How are candidate offers significant for a discussion of language learning opportunities? In lengthy repair sequences, given the new material that they include, they occasion further opportunities for language practice. When offering a candidate item, the teacher is providing a model to the child of what is relevant and appropriate to produce as a response (Pomerantz 1988). In the case of 'd'y'mean an eel?' the model is a single lexical item, although grammatical units could equally be modelled in this way. The teacher leads the child to focus on the item, and further exposes it, by placing it in turn final position and marking it with additional prosodic emphasis. Yet, in the example presented here and others in the dataset, it is not repeated, even following teacher repetition at line 12 . An explanation is that a relevant response to this type of yes/no question is either for the child to confirm T's guess as the correct target, or to give a different version if the guess is incorrect.

\section{SUMMARY AND CONCLUSIONS}

Specialist language teachers use a variety of techniques to initiate repair and supply correction in response to troubles hearing or understanding the children's novel news or story ideas. Given that children with specific speech and language difficulties typically display problems with their production of phonology, syntax and semantics, their novel ideas commonly occasion insertion sequences that deal with the business of correction, other-initiation and self-repair. This paper has documented, in some detail, four distinct types of RI practices that emerged as prevalent patterns in a 
substantial database of 78 cases. It is now worth summarising the key characteristics of these techniques.

1. Non-specific ('general') RIs

- constructed as an open class RI ('pardon') or as a message that the trouble source entails hearing ('say that again') or understanding ('I don't know what that means')

- target the whole, or potentially any aspect, of the child's prior turn

- reveal a 'substantial lack of grasp of what was said' (Schegloff 1997; 524)

- used to elicit a repeat or reformulation of any (or all) of the prior

2. Specific RIs: designedly incomplete utterances

- constructed with minimal components of the child's prior turn ('a:::'; 'she has')

- used as a clue that pinpoints the location of the trouble source

- provide no new lexical information

- used to elicit a repeat of the child's prior or to target an error and prompt self-correction

3. Specific RIs: 'Wh' questions

- constructed as 'wh' questions ('down whe:re.'; 'what's his neighbourhood?')

- used as a clue that pinpoints the nature of the trouble source

- used to elicit further information about the trouble

4. Offers of candidates

- constructed as modulated other correction 'do you mean $X$ '

- provide a new model of the type of information that is needed (Pomerantz 1988), such as a lexical item, but could be grammatical e.g. morphology 
- not suited to eliciting a repeat (uptake) of the model since formed as a yes/no question.

Non-specific RIs are distinguished from specific RIs principally by the degree of information afforded to the child. The former target the trouble source more generally, so the child has a wider domain of prior utterance(s) from which to select in order to formulate a repeat or revision. Specific formats are more focused: they either target the location of the trouble (DIUs) or the nature of the trouble ('wh' questions). DIUs are used to elicit both repeats and prompt self-correction. Furthermore, 'wh' questions include requests for word definition, and these are suited to eliciting the child's display of understanding of lexical items. Whereas offers of candidates provide a linguistic model, they are not taken as opportunities for repeat (or 'uptake', as in Loewen 2004). General' RIs are preceded by less clear child contributions, where the only option is to target the whole/any of the prior. In contrast, specific RIs are possible in contexts where the child has been, at least partially, heard or understood. This affords the opportunity to repeat part of the prior, as in DIUs, or to target a specific component such as in offers of candidates ('Do you mean X?') or 'wh' questions.

Detailed descriptions of repair practices have important implications for practitioners. Studies of repair trajectories in classrooms where children are learning a second language have identified distinctive patterns that are associated with different communicative tasks (Seedhouse 2004). As far as the field of speech and language therapy is concerned, comparable work has provided preliminary insights into interactions between adults and children with specific language impairment (Gardner 2005) and adults with acquired speech disorders (Bloch 2005). In terms of the current study, both teachers and speech and language therapists will gain a richer 
understanding of adults' responses to children's ideas during language interventions, especially when dealing with sources of unclear meaning.

From a methodological perspective, using CA has afforded fresh insights into the participants' behaviours. Whereas Radford et al. (2006) broadened the notions of teacher initiation (I) and child response (R), this study provides fresh insight into feedback (F) practices that initiate repair and correction and the actions accomplished by a range of designs. Although not a primary aim, the study also demonstrates the rich interactional competencies of the children to engage in repair sequences, despite their evident language difficulties. Furthermore, it is evident that in analysing the data of children with speech and language difficulties, external judgements of 'errors' would be misleading. The broader construct of trouble source may be better suited to 'messier' data, whilst the participants' perspectives are key to interpreting the actions accomplished. Yet, as CA has rarely been adopted in studies of such children, there is a considerable amount of work still to do. Future research aims to explore a wider range of lesson and participant contexts and examine in more detail other design features, such as the non-verbal and prosodic features of the interaction.

\section{NOTES}

1. The transcription conventions used in this paper are based on the system originally developed by Gail Jefferson, as reported in Atkinson and Heritage (1984: ix-Xvi).

2. 'Expressive' language difficulties may include some or all of the following: problems with expressive syntax, morphology, articulation, phonology and word finding difficulties. 'Receptive' language difficulties entail problems 
with the comprehension of syntax, morphology and word meanings (ContiRamsden and Botting 1999).

3. 'Pragmatic' language difficulties are defined as problems in using language appropriately in a conversational context despite well-formed syntax (Bishop 2000).

4. I am indebted to anonymous reviewers for several insights in this analysis.

\section{REFERENCES}

Alexander, R. 2001. Culture and Pedagogy: international comparisons in primary education. Oxford UK and Malden USA: Blackwell.

Alexander, R. 2006. Towards dialogic teaching: Rethinking classroom talk. ( $3^{\text {rd }}$ edn.), Dialogos UK: University of Cambridge.

Atkinson, J. and J. Heritage 1984. (eds.): Structures of Social Action: Studies in Conversation Analysis. Cambridge: Cambridge University Press.

Bishop, D.V.M. 2000. 'Pragmatic language impairment: A correlate of SLI, a distinct subgroup or part of the autistic continuum?' In D.V.M. Bishop and L.B. Leonard (eds.) Speech and language impairments in children: causes, characteristics and outcomes. Psychology Press.

Bloch, S. 2005. 'Co-constructing meaning in acquired speech disorders: word and letter repetition in the construction of turns.' In K. Richards and P. Seedhouse (eds.) Applying conversation analysis. Basingstoke: Palgrave Macmillan. 
Button, G. and N. Casey 1984. 'Generating topic: the use of topic initial elicitors.' In J.M. Atkinson and J. Heritage (eds.): Structures of Social Action: Studies in Conversation Analysis. Cambridge: Cambridge University Press.

Button, G. and N. Casey 1985. 'Topic nomination and topic pursuit.' Human Studies 8: 3-55.

Cazden, C. B. 2001. Classroom Discourse: The Language of Teaching and Learning. ( $2^{\text {nd }}$. edn.), Portsmouth: Heinemann.

Conti-Ramsden, G. and N. Botting 1999. 'Classification of children with specific language impairment.' Journal of Speech, Language and Hearing Research 42: 1195 1204.

Dockrell, J. and D. Messer 1999. Children's Language and Communication Difficulties: Understanding, identification and intervention. London: Cassell.

Dockrell, J., G. Lindsay, B. Letchford and C. Mackie 2006. 'Educational provision for children with specific speech and language difficulties: perspectives of speech and language therapy service managers.' International Journal of Language and Communication Disorders 41/4: 423-

Drew, P. 1997. “"Open” class repair initiators in response to sequential sources of trouble in conversation.' Journal of Pragmatics 28/1: 69-101.

Edwards, A.D. and Westgate, D.P.G. 1994. Investigating Classroom Talk. (2 ${ }^{\text {nd }}$ edn.). London: Falmer Press.

Gardner, H. 2005. 'A comparison of a mother and a therapist working on child speech.’ In K. Richards and P. Seedhouse (eds.) Applying conversation analysis. Basingstoke: Palgrave Macmillan.

Jefferson, G. 1987. 'On exposed and embedded correction in conversation.' In G. 
Button and J. Lee (eds.), Talk and Social Organization. Clevedon: Multilingual Matters.

Koshik, I. 2002. 'Designedly incomplete utterances: A pedagogical practice for eliciting knowledge displays in error correction sequences.' Research on Language and Social Interaction 35/3: 277-309.

Law, J., Lindsay, G., Peacey, N., Gasgoigne, M., Soloff, N., AUTHOR and Band, S. 2000. Provision for Children with Speech and Language Needs in England and Wales. London: DfEE.

Leonard, L. 2000. Children with Specific Language Impairment. Cambridge, MA: MIT Press.

Loewen, S. 2004. 'Uptake in incidental focus on form in meaning-focused ESL lessons.' Language Learning 54/1: 153-188.

Lyster, R. 1998. 'Negotiation of form, recasts and explicit correction in relation to error types and learner repair in immersion classrooms.' Language Learning 48: 183218.

Macbeth, D. 2004. 'The relevance of repair for classroom correction.' Language in Society 33: 703-736.

Mehan, H. 1979. “"What time is it Denise?”: Asking known information questions in classroom discourse.' Theory into Practice 18/4: 285-294.

Mercer, N. 1995. The guided construction of knowledge: Talk amongst teachers and learners. Clevedon: Multilingual Matters.

Mercer, N. 2000. Words and Minds: How we use language to think together. London: Routledge.

Mercer, N. and K. Littleton 2007. Dialogue and the development of children's thinking: A sociocultural approach. London: Routledge. 
Mroz, M., F. Smith and F. Hardman 2000. 'The Discourse of the Literacy Hour.' Cambridge Journal of Education 30/3: 379-390.

Nystrand, M. 1997. Opening Dialogue: Understanding the Dynamics of Language and Learning in the English Classroom. New York: Teachers College Press.

Pomerantz, A. 1988. 'Offering a candidate answer.' Communication Monographs 55: 360-373.

Radford, J. and C. Tarplee 2000. 'The management of conversational topic by a tenyear-old child with pragmatic difficulty.' Clinical Linguistics and Phonetics 14/5: 387-403.

Radford, J. and J. Ireson 2006. 'Developing language skills through dialogic discourse.' AFASIC Abstract Spring.

Radford, J., J. Ireson and M. Mahon 2006. 'Triadic dialogue in oral communication tasks: what are the implications for language learning?' Language and Education 20/3: 191-210.

Ridley, J., J. Radford and M. Mahon 2002. 'How do teachers manage topic and repair?' Child Language Teaching and Therapy 18/1: 43-58.

Sadler, J. and K. Mogford-Bevan 1997. 'Teacher talk with children with language disorders: four case studies 2.' Child Language Teaching and Therapy 11: 37-58.

Schegloff, E. A. 1972. 'Notes on a conversational practice.' In D. Sudnow (ed.) Studies in Social Interaction. New York: Free Press.

Schegloff, E. A. 1997. 'Practices and actions: Boundary cases of other-initiated repair.' Discourse Processes 23: 499-545.

Schegloff, E. A., G. Jefferson, and H. Sacks 1977. 'The preference for selfcorrection in the organization of repair in conversation.' Language 53: 361-382. 
Seedhouse, P. 2004. 'The interactional architecture of the language classroom.'

Malden, Mass: Blackwell.

Sinclair, J. M. and R. M. Coulthard 1975. 'Towards an analysis of discourse: The English used by teachers and pupils.' London: Oxford University Press.

Smith, F., F. Hardman, K. Wall. and M. Mroz 2004. 'Interactive whole class teaching in the national Literacy and Numeracy Strategies.' British Educational Research Journal 30/3: 395-411.

Skidmore, D. 2000. 'From pedagogical dialogue to dialogical pedagogy.' Language and Education 14/4: 283-96.

Wells, G. 1993. 'Re-evaluating the IRF Sequence: a proposal for the articulation of theories of activity and discourse for the analysis of teaching and learning in the classroom.' Linguistics and Education 5: 1-37.

Table 1: Children's specific speech and language difficulties

$\begin{array}{cccccccccc}\text { Child } & \text { Age } & \begin{array}{c}\text { Gend } \\ \text { er }\end{array} & \begin{array}{c}\text { Recep- } \\ \text { tive }\end{array} & \begin{array}{c}\text { Express } \\ \text { ive } \\ \text { syntax }\end{array} & \begin{array}{c}\text { Phonol- } \\ \text { ogy }\end{array} & \begin{array}{c}\text { Verbal } \\ \text { dysprax } \\ \text { ia }\end{array} & \begin{array}{c}\text { Nam- } \\ \text { ing }\end{array} & \begin{array}{c}\text { Word } \\ \text { mean- } \\ \text { ing }\end{array} & \begin{array}{c}\text { Prag- } \\ \text { matics }\end{array} \\ \text { A } & 8 \mathrm{y} 7 \mathrm{~m} & \mathrm{~F} & 3 & 2 & 0 & 0 & 1 & 2 & 1 \\ \mathrm{~B} & 8 \mathrm{y} 3 \mathrm{~m} & \mathrm{~F} & 2 & 2 & 0 & 0 & 2 & 2 & 1 \\ \mathrm{C} & 4 \mathrm{y} 4 \mathrm{~m} & \mathrm{M} & 2 & 2 & 1 & 0 & 2 & 2 & 1 \\ \mathrm{D} & 4 \mathrm{y} 8 \mathrm{~m} & \mathrm{~F} & 3 & 3 & 2 & 0 & 3 & 3 & 0 \\ \text { E } & 5 \mathrm{y} 10 \mathrm{~m} & \mathrm{~F} & 3 & 3 & 1 & 0 & 2 & 2 & 1 \\ \text { F } & 5 \mathrm{y} 5 \mathrm{~m} & \mathrm{~F} & 3 & 3 & 1 & 0 & 3 & 3 & 3\end{array}$

Key: $0=$ none, $1=$ mild, $2=$ moderate, $3=$ severe 


\section{Transcription key}

(0.5) The number in brackets indicates silence by tenths of seconds.

(.) A dot enclosed in a bracket indicates a gap in the talk of less than twotenths of a second.

$=\quad$ The equals sign indicates 'latching' between utterances.

[ ] Square brackets between adjacent lines of concurrent speech indicate the onset and end of a spate of overlapping talk.

.hh A dot before an ' $h$ ' indicates speaker in-breath. The more h's the longer the breath.

hh An ' $h$ ' indicates an out-breath. The more h's the longer the breath.

((points $))$ A description enclosed in a bracket, and written in italics, indicates a non-verbal activity. For example ((points at picture)).

- $\quad$ A dash indicates a sharp cut-off of the prior word or sound.

::: Colons indicate that the speaker has stretched the preceding sound or letter. The more colons the greater the extent of the stretching.

! Exclamation marks indicate an animated or emphatic tone.

( ) Empty parentheses indicate the presence of an unclear fragment of tape.

(guess) The words within a single bracket indicate the transcriber's best guess at an unclear utterance.

A full stop indicates a stopping fall in tone. It does not necessarily indicate the end of a sentence.

A comma indicates a 'continuing' intonation.

? $\quad$ A question mark indicates a rising inflection. It does not necessarily indicate a question.

$\uparrow \downarrow \quad$ Pointed arrows indicate a marked falling or rising intonational shift. They are placed immediately before the onset of the shift.

under Underlined fragments indicate speaker emphasis.

CAPITAL Words in capitals mark a section of speech noticeably louder than that $\mathrm{S}$ surrounding it. 
Degree signs are used to indicate that the talk they encompass is spoken noticeably quieter than the surrounding talk.

'More than' and 'less than' signs indicate that the talk they encompass

$><\quad$ was produced noticeably quicker than the surrounding talk.

$\rightarrow \quad$ Arrows in

The transcription conventions used in this paper are based on the system originally developed by Gail Jefferson, as reported in Atkinson and Heritage (1984: ix-xvi). 